Fabio Morábito

\title{
El "picnic", o el descenso de los árboles
}

En el que quizá es su mejor libro, El barón rampante, Italo Calvino imagina a un muchacho, el barón Cosimo Piovasco, que ha decidido pasar toda su vida en los árboles y no volver a pisar el suelo. Se hace hombre entre las ramas, donde adquiere una sólida cultura que le permitirá mantener una abundante correspondencia con algunas de las luminarias más célebres de su época. Lejos de volverse un ser rústico o primitivo, su exilio arbóreo lo convierte en un ciudadano del mundo, como si hubiera encontrado en las copas de los árboles la altura adecuada para, sin dejar de ser un hombre de su tiempo, salvarse de cualquier localismo sofocante. Encuentra en los árboles, puede decirse, la esencia misma de la urbanidad, entendida no sólo como buena educación sino como cualidad de la vida urbana. Su aposento a unos cuantos metros del suelo y siempre ventilado se torna el símbolo de su espíritu abierto e indagador. Se establece así, en la novela, una relación sutil entre la ciudad, entendida como el espacio de las ideas y del progreso espiritual, y las ramas de los árboles; y en esta relación inesperada estriba el verdadero hallazgo de Calvino y el núcleo poético de su libro. ¿Qué es la ciudad, en esencia, sino un esfuerzo de elevación para desprenderse de la tiranía del suelo y recobrar mediante su peculiar superposición de pisos y a tra- 
vés de sus numerosos cruces, intersecciones, puentes y desniveles, el mundo elevado y bullanguero de las ramas en el que nuestros ancestros se desplazaban organizados en clanes? ¿No es la ciudad entonces una forma de regresar a ese antiguo balanceo de rama en rama y de árbol en árbol, a ese gusto por la improvisación y la ligereza que sólo era posible en las alturas y que la vida agrícola, regular, monótona y roturadora, suprimió de tajo?

Se me dirá que el suelo siempre ejerció una fuerte atracción en nuestros antepasados arborícolas. Es cierto. Era sinónimo de peligro, pero también de riqueza de alimento. En el suelo los frutos caídos de los árboles se acumulaban en espera de que alguien los recogiera. Los apresurados descensos en busca de un botín fácil debían de ser algo más que esporádicos, por lo que el suelo siempre supuso para la especie, además de un lugar lleno de amenaza, un espacio de grandes oportunidades. A la larga, de hecho, su llamado fue más poderoso que el mundo frugal y seguro de las alturas. Pero el hecho de habernos sometido al imperio de la planicie no ha borrado en nosotros el eco del alboroto de las copas elevadas. Jaloneados por esos dos extremos, buscamos incesantemente reunirlos y el espacio concreto de esa reunión soñada es el suelo abrigado por la sombra de los árboles, es decir el lugar del primer descenso de las ramas, desde el cual, en caso necesario, todavía es posible trepar para ponerse a salvo.

Ese lugar mítico del primer descenso, que reúne de manera ideal la riqueza de los frutos caídos y la seguridad de las alturas, ha dado vida a nuestros jardines y tiene su cabal expresión alimenticia en el picnic, que es la representación de la primera comida bajo los árboles o, para ser más precisos, a la sombra de los árboles, ya no arriba de ellos. Esa primera comida estable, alejada del vértigo de las ramas, pero todavía muy próxima a ellas, es también la primera comida circular, algo que las ramas, debido a su forma bifurcante y desnivelada, eran inca- 
paces de proporcionarnos. Sólo en el suelo la comida del clan, que arriba de los árboles no pasaba de ser una agrupación confusa, se vuelve verdadera reunión. Sólo abajo puede surgir la rueda y la comunión. Por eso es impensable un picnic de un solo individuo. El picnic es por naturaleza gregario y además expansivo, se presta fácilmente al contacto con otros picnics, y los niños y las pelotas, ambos seres rodantes, suelen ser los causantes más frecuentes de esas conexiones entre un picnic y otro. Y esta propensión del picnic a la alianza y al intercambio responde al temor que siempre acompañó los descensos al suelo de nuestros antepasados, descensos que representan el precedente más remoto del día de campo, la semilla de nuestro hábito de abandonar las cuatro paredes donde vivimos para disfrutar de algo apetitoso al aire libre.

Es más, en rigor, sólo algo al aire libre es apetitoso, sólo algo consumido junto a la base de los árboles nos colma de placer culinario, sólo un picnic nos deja de veras hartos, porque en él se da esa especial conjunción de gula e inquietud (inquietud derivada de haber descendido de nuestros elevados aposentos), y de apetito y zozobra (zozobra por la noche, la lluvia, los animales, el bosque, los eventuales violadores), que hacen que el acto de comer vuelva a ser el gesto primario e infantil de recoger del suelo algo comestible y maduro. Ese gesto es el alma del picnic y por eso, lo mismo que es impensable un picnic individual, no tiene sentido un picnic desabrido. ¿Quién haría un picnic con comida para enfermos? La primera comida bajo los árboles, por representar el fin de la frugalidad imperante en las alturas, debe tener un toque de suntuosidad, como suntuoso debía de parecerles a nuestros antepasados el suelo regado de diferentes frutos. Un picnic que adolezca de algún atractivo suculento, de alguna delicia cremosa, es pues un picnic incompleto, e igualmente fallido es un picnic parco, que nos someta fuera de casa a la tiranía de las porciones que rige dentro de ella. Siendo el picnic, en su descripción más es- 
cueta, una comida sin mesa, todo lo que la mesa significa: cierta formalidad al comer, que se acompaña de la repartición cuidadosa del alimento y de cierto grado de espiritualización del mismo, desaparece en él, y la comida recupera su sentido primitivo de botín y captura. Por eso, en el picnic, el valor esencial es la suculencia, no la exquisitez, y la suculencia, que nos lleva a "chuparnos los dedos" del gusto y que la mesa ha atenuado con la acción formalizadora que ejerce sobre la comida, está ligada al sentimiento de habernos apropiado de algo que otros codiciaban. Algo suculento es algo que en alguna medida nos hemos robado o hemos hallado de forma sorpresiva. Y así, al aire libre, comiendo sobre la hierba, cada bocado es más bocado porque sentimos más intensamente que lo que llevamos a la boca pudo haber sido de otros. Por esa razón, aun en el picnic ideal, que sería el picnic situado en las ramas de los árboles, en el cual se conjugaría la protección de la altura con la abundancia propia del suelo, no correríamos el riesgo de que la atenuación del peligro mermara la delicia del alimento. Aun allá arriba, en el picnic rampante, al abrigo de cualquier peligro, todavía tendríamos que temer, como bien sabían nuestros antepasados, el zarpazo de la gravedad, siempre lista a hurtarnos al menor descuido o torpeza el bocado más escogido para regalárselo, por ejemplo, a algún picnic de abajo. 